\title{
Sesenta y seis años de la alcahueta en la escena teatral en México
}

«Señora, ten tú el tiempo que no ande, terné yo mi forma que no mude». Auto IV, La Celestina.

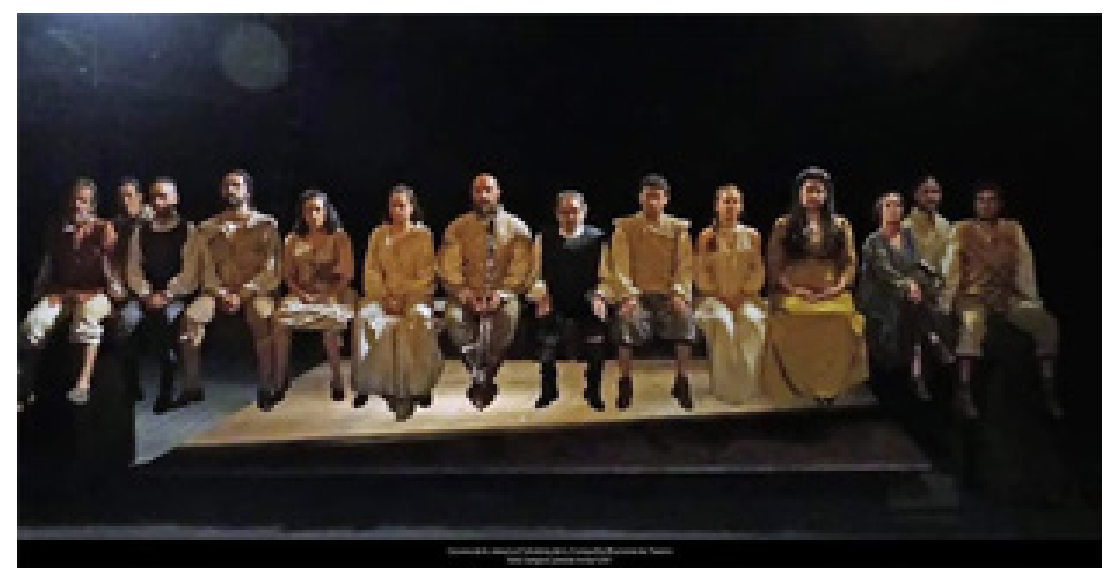

Pasaron ya 66 años desde aquel 31 de julio de 1953, fecha en la que Álvaro Custodio y su Teatro Español de México presentaron la adaptación de Celestina en la Sala Molière del Instituto Francés de la América Latina, en la Ciudad de México. La puesta en escena sucedió con tal surrealismo tragicómico que le siguieron ocho años de censura (desde 1960 hasta 1968). Además, generó una anécdota graciosa por el tono de la obra: la búsqueda por parte de las autoridades capitalinas del autor Fernando de Rojas para reprenderlo por escribir tan escandalosa obra. ${ }^{1}$ Estas cuestiones - ya conocidas en la historia de la escena teatral celestinesca - no se terminan, al contrario, se suman otras, algunas veces gratas y memorables

Una de ellas aconteció el 30 de diciembre de 2018, en la Sala Héctor Mendoza de la Compañía Nacional de Teatro, un hecho que ahora es

1.- Kathleen Kish, "Celestina sale a las tablas en México», Actas del XV Congreso de la Asociación Internacional de Hispanistas "Las dos orillas», volumen 1, celebrado del 19 al 24 de julio de 2004 en Monterrey. Fondo de Cultura Económica, 2007, pp. 379-388. 
parte de la historia: el féretro con el cuerpo de Rosenda Monteros recibió un homenaje en el escenario. La voz de la maestra y actriz leyendo La Celestina en un día de ensayo aderezaba los honores. ${ }^{2}$ Rosenda Monteros perteneció al grupo de actores de la adaptación de Álvaro Custodio, interpretó a Areúsa y logró convertirse en una de las grandes actrices e impulsoras del teatro de los Siglos de Oro. En 2018, empezó a dirigir su propia versión de La Celestina. Desafortunadamente, en diciembre de ese año se apagaría su luz, pero no el proyecto que (en homenaje póstumo) retomó sabiamente Ruby Tagle del que fuera el postrero trabajo de la reconocida directora y actriz.

Esta nueva puesta en escena se estrenó el 9 de mayo de 2019 en la Sala Héctor Mendoza por la Compañía Nacional de Teatro. El papel de Celestina está a cargo de Laura Padilla, su actuación alcanza en varios momentos el ideal celestinesco de abarcarlo todo con la voz y no deja lugar a dudas: ella es la protagonista de esta historia. Paulina Treviño, con su ronca voz de cisne, interpreta a la hermosa Melibea, su actuación se caracteriza por un tono colérico del loco amor que la invade y de las dudas que surgen en ella por ser una moza encerrada. Calisto, ejecutado por Misha Aries de la Cantolla, es un personaje oscuro, opacado por sus mozos los cuales invaden el escenario con sus actuaciones, dejando apagado al noble. El cambio de mozo leal a traidor y embriagado de holgar es perceptible en Pármeno, aunque a veces paródico. Adrián Aguirre recrea al mozo con la actitud infantil del que se cree sabio a pesar de no ser viejo. En cambio, Eduardo Candas, Sempronio, tiene tintes bufonescos en su interpretación, lo cual plantea el principal problema de adaptación del texto medieval a la comedia de los Siglos de Oro, dicho en otras palabras, le quita sobriedad al personaje y lo convierte en grotesco.

Pilar Padilla y Ana Paola Loaiza, Elicia y Areúsa logran un buen equilibrio en su actuación y dejan que Celestina brille por encima de ellas, pero con actuaciones claras y contundentes. Elicia se nos presenta como muy brava mujer; y Areúsa (que conocemos como recatada en el encuentro con Pármeno) no muestra ese matiz del décimo quinto Auto. Lucrecia, Azalia Ortiz, tiene pocos diálogos que equilibra con gesticulaciones y mímicas propias del teatro de Siglos de Oro. Lo que puede notarse es que ella, como Sempronio, están enamorados de Calisto y Melibea - los criados viven para alcanzar los deseos de sus amos, por lo menos sirviendo de alcahuetes. Finalmente, Gastón Melo nos ofrece un entrañable Pleberio en parte por la omisión de la madre de Melibea, Alisa. Se observa una relación entrañable del padre con su hija, lo cual prepara al público para conmoverse en el planctus, breve, pero desolador en tan magnífica voz. 
La escenografía de esta puesta en escena es la otra protagonista: un tablado en forma diagonal y un puente, mesa, camino móvil que se traslada de principio a fin por el escenario. Esta disposición da una perfecta sensación de movimiento en toda la obra, los ventanales góticos le dan el espíritu medieval al espacio escénico. La escala puesta ahí en todo momento nos recuerda que algo no terminará bien. En el mismo nivel escenográfi$\mathrm{co}$, hay un instrumento musical que sorprende porque no es medieval, se trata de un clarinete bajo que, a decir de la experiencia de un espectador entrevistado, anticipa el tono de la obra.

$\mathrm{Al}$ entrar al teatro, en una inversión del espacio, los personajes reciben al público formados en hilera sobre la plataforma móvil (ver la foto) y te observan mientras buscas tu asiento, resulta intimidante el breve momento en que ellos actúan de público y el público somos los actores ¿¿ué acaso no es lo mismo que nos descubre La Celestina en cada lectura: que es ella quien nos mira y no nosotros a ella? Inicia la música con notas antiguas para entrar en ambiente, Lucrecia luce soñadora: ¿sueña los sueños de Melibea? Celestina nos mira, quizás buscando un virgo que arreglar entre el público, Melibea recostada, Pleberio bendice a su hija mientras Pármeno reza. Salen los actores de escena, Pleberio recita el argumento. Inicia el primer Auto, Melibea con la espalda descubierta y los senos al aire (de espaldas al público) es perfumada por Lucrecia. Calisto salta la huerta, mira a Melibea semidesnuda y dice: «En esto veo, Melibea la grandeza de Dios».

En cuanto a la estructura, la adaptación está concebida en forma lineal, sólo hasta el encuentro de los enamorados conjunta varios autos con la finalidad de concluir la obra. Al fondo del escenario se observa una suerte de calle de pueblo, desde el público vemos (continuamente) personajes andando de un lado a otro, personajes que no distraen la acción, pero se mantienen como comparsa de lo que acontece en escena. En el nivel del lenguaje, esta versión privilegia refranes, proverbios y sentencias de la tragicomedia con su lenguaje arcaico — sin pronunciación fonética. En voz de los intérpretes acarician el oído del público (que muchas veces sonríe cómplice y otras, se carcajea por lo bajo). Sin embargo, esta intervención de sentencias se siente apresurada en escena, adolece de los tiempos y pausas que puede lograr una lectura en voz alta, pero la dicción es magnífica. En palabras de Ruby Tagle, la intención de Rosenda Monteros consistía en la siguiente: "quería marcar un paso adelante a la forma de hablar ahora, como un homenaje personal al lenguaje castellano antiguo». ${ }^{3}$

$\mathrm{Al}$ tener una escenografía austera a su disposición, los actores usan el piso, se acuestan en él cuando manifiestan sus deseos bajos. Así aconte-

3.- Fabiola Palapa Quijas, La Celestina sigue vigente porque aborda la «corrupción de la pobreza y la codicia", consultado en el sitio <https://www.jornada.com.mx/ultimas/2019/05/12/ la-celestina-sigue-vigente-por-la-201ccorrupcion-de-la-pureza-y-codicia201d-3533.html>. 
ce el primer auto. En el segundo, Calisto propina un remedo de paliza a Pármeno, acción anticipadora de la pérdida de lealtad hacia su amo. En el tercer auto, el conjuro es un montaje artístico: se coloca una figura gótica que da sombra y luz, en este espacio Celestina se mueve cual serpiente al invocar a Plutón; la sutileza de esta escena consiste en que Melibea (ya en el décimo auto) tendrá el mismo trasiego, como se ha hecho notar en diversos estudios críticos de las antelaciones en la obra. Melibea se contagia de loco amor por el cordón recibido en el cuarto auto, el eje o pretexto en esta adaptación lo da la magia. Melibea, herida en su honor, violenta físicamente a Celestina. Todo, mientras un espejo cuelga a un lado y refleja la escena como si se tratara de un cuadro renacentista. En el quinto auto, Sempronio sospecha la traición de la vieja honrada mientras se traslada una y otra vez sobre el escenario móvil, al mismo tiempo que Celestina recita las líneas ya conocidas por sus lectores. El sexto auto tiene un cuadro principal: la toma por Calisto del cordón de Melibea. Acostado, halando de manos de Celestina, quién lo sostiene con firmeza en un segundo cuadro renacentista, lo cual le otorga un poder a la imagen y a los movimientos teatrales en esta puesta.

En el encuentro de Pármeno y Areúsa, en el séptimo auto, Celestina cita diversos pasajes que son un deleite para el espectador-oidor. El discurso que trata sobre las ventajas del número dos acompaña a las escenas eróticas entre Celestina y Areúsa (estos cuadros son bastante cuidados) y, posteriormente, se observan las participaciones de Pármeno y Areúsa que resultan una parodia. El octavo auto refrenda débilmente el acuerdo de amistad entre Sempronio y Pármeno. Éste es un acuerdo alegre, producto del embelesamiento y robo a la despensa de Calisto. En el episodio del banquete (en el auto noveno), el discurso del vino y las glorias pasadas tienen la intención y el efectismo escénico.

El décimo auto le pertenece a la actriz que interpreta a Melibea: herida de amor se retuerce en el piso, satisface manualmente sus pasiones y se entrega mansa a Celestina. En el onceno auto, Celestina comunica con maestría su buena empresa a Calisto. Hasta aquí, hemos visto muchas veces las dotes de manipulación de la vieja, que siempre anda cargada con un disfraz de indefensión. El doceno auto requiere un gran esfuerzo físico de parte de Calisto ya que su cuerpo queda colgado del puente movedizo; esta función corporal y la posición de Melibea (ubicada en la parte de arriba) simula el instante del primer encuentro en el balcón. Hay una necesidad de aliviar a Calisto de tal fatiga. Más delante de la puesta, la muerte de Celestina en manos de Sempronio es gris, aunque la defensa colérica de Celestina «¿Quitásteme de la putería?» deja claro que las razones de Pármeno y Sempronio son improcedentes.

La alcahueta es víctima de sus secuaces. El asesinato trasciende por medio de los cantos plañideros de Elicia y Areúsa, con su cuerpo inerte en el escenario llega el momento sobrio de la puesta. 
El treceno auto muestra la reacción desenfadada de Calisto ante la muerte de sus criados, ante un Sosia magníficamente vestido, Calisto reitera la importancia de alcanzar carnalmente a Melibea. El catorceno auto y décimo nono se unen al final de la adaptación teatral, excluyendo los restantes para mostrar el encuentro amoroso casi cortés de Calisto y Melibea; en tal confluencia sólo hay un abrazo con los ropajes puestos, cabe mencionar que se echa en falta el arrojo del desplumador de gallinas. Este apartado, termina con una simulada caída de la escala que no llega al piso, lo cual hubiera sido sutil, dado que los personajes estaban unidos al piso cuando mostraban sus pasiones. En el veinteno auto, Melibea protagoniza una acción simultánea: da sus razones a Pleberio, entretanto camina al borde del puente, causando el vértigo de una caída inminente. En el auto vigésimo primero, el diálogo de Melibea con su padre es amplio; por un lado, se agradece que se extienda este momento, por otro, contando con tan magnífico actor, el planctus de Pleberio se hace breve dejándonos al final in hac lachrymarum valle.

Se termina la puesta en escena y los actores reciben aplausos con el público de pie, la temporada tiene las entradas agotadas, Celestina brilla en el teatro, pero tiene el inconveniente del breve tiempo, casi tres horas con intermedio. Álvaro Custodio y Criado de Val, en el primer Congreso de Celestina impulsaron un acuerdo: la lectura total de la obra en un festival anual que no se llegó a realizar nunca. ${ }^{4} \mathrm{Tal}$ acuerdo indagaba por una lectura total de la obra que privilegiara la voz antes que la escenografía, las luces y el vestuario con un actor que siguiera las indicaciones de Alonso de Proaza y tuviera la energía de leer durante nueve horas ${ }^{5}$ y que tal vez sólo tuviera o tenga un público celestinista.

El público de esta puesta es universitario, los hay quienes tienen noticia de la obra y la conocen y los que son asiduos al teatro clásico les resulta satisfactoria; hay quien luce emocionado, otros confusos en cuanto a los hechos se refiere, pero Celestina está llegando a la gente con esta versión. Para el espectador no especializado en Celestina la adaptación es un torrente de palabras; para los conocedores de la tragicomedia son goterones de agua fresca en un mar de sed.

Guadalupe Lezama Limias Universidad Autónoma Metropolitana Cátedra extraordinaria "Juan Ruíz de Alarcón» La Celestina en voz alta, UNAM

4.- Álvaro Custodio, «La Celestina como experiencia teatral», Celestinesca 3.1 (1979), pp. 33-38.

5.- Joseph T. Snow refiere a la lectura primigenia de Celestina en «La gran Celestina, ahora en versión de José Luis Goméz», Cuaderno Pedagógico 55, publicación del teatro de la comedia "Celestina» bajo la dirección de José Luis Gómez. Con la coproducción: CNTC del Teatro de La Abadía, cuyo estreno ocurrió en 2016, consultado en el sitio <http://teatroclasico.mcu. es/2016/04/15/celestina/>. 


\section{Bibliografía}

Custodio, Álvaro, «La Celestina como experiencia teatral», Celestinesca 3.1 (1979), pp. 33-38.

KisH, Kathleen, "Celestina sale a las tablas en México", Actas del XV Congreso de la Asociación Internacional de Hispanistas "Las dos orillas", Monterrey, México, del 19 al 24 de julio de 2004, México, Fondo de Cultura Económica, vol. 1, 2007, pp. 379-388.

Martínez, Alegría, «Recuerdos de Rosenda Monteros», Peripecia, en red, consultad: <https://www.milenio.com/cultura/laberinto/recuerdosde-rosenda-monteros $>$.

Palapa Quijas, Fabiola, La Celestina sigue vigente porque aborda la "corrupción de la pobreza y la codicia», en red: <https://www.jornada.com.mx/ultimas/2019/05/12/la-celestina-sigue-vigente-por-la201ccorrupcion-de-la-pureza-y-codicia201d-3533.html>.

Snow, Joseph, T., "La gran Celestina, ahora en versión de José Luis Goméz», Cuaderno Pedagógico 55, publicación del teatro de la comedia "Celestina» bajo la dirección de José Luis Gómez. Con la coproducción: CNTC del Teatro de La Abadía, cuyo estreno ocurrió en 2016, en red: <http://teatroclasico.mcu.es/2016/04/15/celestina/>. 